\title{
ReSEARChArticle \\ Assessment of genetic diversity through morphological characterization in chickpea (Cicer arietinum L.)
}

\author{
Kadiyala Naga Suresh and Gabriyal M. Lal
}

\begin{abstract}
SUMMARY
The experiment was conducted at Field Experimentation Centre, Department of Genetics and Plant Breeding, Sam Higginbottom University of Agriculture Technology and Sciences, Prayagraj during Rabi 2019-2020 in Randomized Block Design with three replications. The investigation was prevailed to examine the 40 genotypes along with one check (PUSA 362) to study the genetic variability, genetic advance, heritability and Genetic diversity. Analysis of variance exhibited significant differences among the genotypes for all the characters indicating presence of good amount of variability among the genotypes for all the characters used in study. high GCV and PCV were observed for biological yield (31.5 and 39.47). High heritability $(>80 \%)$ was recorded for character Days to $50 \%$ flowering $(89 \%)$ followed by days to maturity (87\%), days to $50 \%$ flowering $(86 \%)$, seed weight (82\%). Higher genetic advance was observed for no. of seeds per plant (39.64) followed by no. of pods per plant (31.77), biological yield (21.07), days to 50\% maturity (11.41) and plant height (11.03). $\mathrm{D}^{2}$ values showed adequate genetic diversity among the genotypes studied. On the basis of $\mathrm{D}^{2}$ values all the genotypes were grouped into five clusters with varying number of genotypes in the clusters. The maximum genetic distance (D) of 54.46 was found between the clusters IV and II. Greater the divergence between the 2 clusters, wider is that the genetic diversity within the genotypes. The cluster mean for days to 50 per cent flowering varied from 84.00 (V) to 108 (III). The cluster mean for days to 50 per cent pod setting varied from 86.67 (IV) to 120.67 (II). The cluster mean for 100 seed weight was maximum in (cluster II) 24.33 and minimum in (cluster IV) 20. The cluster mean for harvest index was maximum in (cluster II) 56.71 and minimum in (cluster V) 38.56. The cluster mean for biological yield was maximum in (cluster III) 53.13 and minimum in (cluster II) 36.2. The cluster mean for seed yield was maximum in (cluster III) 20.93 and minimum in (cluster V) 13.2. Therefore, the genotypes present in these clusters can be used for future hybridization.
\end{abstract}

\section{MEMBERS OF THE RESEARCH FORUM}

Author to be contacted :

Kadiyala Naga Suresh, Department of Genetics and Plant Breeding, Sam Higginbottom University of Agriculture Technology and Sciences, Prayagraj (U.P.) India

Email : sureshkadiyala25@gmail.com

Address of the Co-authors:

Gabriyal M. Lal, Department of Genetics and Plant Breeding, Sam Higginbottom University of Agriculture Technology and Sciences, Prayagraj (U.P.) India
Key Words : Chickpea, Variability, Genetic advance, Heritability, Genetic diversity

How to cite this article : Naga Suresh, Kadiyala and Lal, Gabriyal M. (2021). Assessment of genetic diversity through morphological characterization in chickpea (Cicer arietinum L.). Internat. J. Plant Sci., 16 (2): 109-117, DOI: 10.15740/HAS/IJPS/16.2/109-117, Copyright@2021: Hind Agri-Horticultural Society.

Article chronicle : Received : 26.02.2021; Revised : 17.03.2021; Accepted : 17.04.2021 